\title{
NEURONAL ACTIVITY PATTERNS IN THE DEVELOPING BARREL CORTEX
}

\author{
HEIKO J. LUHMANN ${ }^{\text {a* }}$ AND RUSTEM KHAZIPOV ${ }^{\mathrm{b}, \mathrm{c}}$ \\ a Institute of Physiology, University Medical Center of the \\ Johannes Gutenberg University Mainz, Duesbergweg 6, \\ $D$-55128 Mainz, Germany \\ b INMED - INSERM, Aix-Marseille University, Marseille \\ 13273, France \\ c Laboratory of Neurobiology, Kazan Federal University, \\ Kazan 420008, Russia
}

\begin{abstract}
The developing barrel cortex reveals a rich repertoire of neuronal activity patterns, which have been also found in other sensory neocortical areas and in other species including the somatosensory cortex of preterm human infants. The earliest stage is characterized by asynchronous, sparse single-cell firing at low frequencies. During the second stage neurons show correlated firing, which is initially mediated by electrical synapses and subsequently transforms into network bursts depending on chemical synapses. Activity patterns during this second stage are synchronous plateau assemblies, delta waves, spindle bursts and early gamma oscillations (EGOs). In newborn rodents spindle bursts and EGOs occur spontaneously or can be elicited by sensory stimulation and synchronize the activity in a barrel-related columnar network with topographic organization at the day of birth. Interfering with this early activity causes a disturbance in the development of the cortical architecture, indicating that spindle bursts and EGOs influence the formation of cortical columns. Early neuronal activity also controls the rate of programed cell death in the developing barrel cortex, suggesting that spindle bursts and EGOs are physiological activity patterns particularly suited to suppress apoptosis. It remains to be studied in more detail how these different neocortical activity patterns control early developmental processes such as formation of synapses, microcircuits, topographic maps and large-scale networks.
\end{abstract}

This article is part of a Special Issue entitled: Barrel Cortex. (C) 2017 IBRO. Published by Elsevier Ltd. All rights reserved.

Key words: spontaneous activity, sensory-evoked activity, development, rodents, GABA, review.

\footnotetext{
${ }^{*}$ Corresponding author.

E-mail address: luhmann@uni-mainz.de (H. J. Luhmann).

Abbreviations: BDNF, brain-derived neurotrophic factor; cENOs, cortical early network oscillations; CREB, cAMP response elementbinding; EGOs, early gamma oscillations; FS, fast spiking; MEAs, multi-electrode arrays; SPAs, synchronous plateau assemblies; Trk, tropomyosin-related kinase; TTX, tetrodotoxin; VSD, voltage-sensitive dye.
}

http://dx.doi.org/10.1016/j.neuroscience.2017.05.025

0306-4522/C 2017 IBRO. Published by Elsevier Ltd. All rights reserved.

\section{INTRODUCTION}

It is well accepted that electrical activity plays a very important role in the developing brain. During so-called critical periods brain regions processing sensory information (specific brainstem and thalamic nuclei, sensory neocortical areas) undergo substantial structural and functional modifications based on the electrical activity arising from the sensory periphery (for review Erzurumlu and Gaspar, 2012; Espinosa and Stryker, 2012; Kral, 2013). These experience-dependent modifications occur at the synaptic as well as at the large-scale network level. It is often ignored that the brain reveals complex electrical activity patterns during prenatal and early postnatal development, clearly before sensory experience gained through the exploration modifies neuronal circuits during the critical periods. Although the concept for the existence of a precritical period has emerged over the last decade (for review Feller and Scanziani, 2005; Khazipov and Luhmann, 2006; Blankenship and Feller, 2010), the complexity and the role of spontaneous and evoked activity patterns during earliest stages of brain development has been addressed in detail only more recently. In the spinal cord and in supraspinal circuits electrical activity is evident from the beginning of development and controls cell generation versus cell death, differentiation, axonal guidance, synapse formation, neurotransmitter specification, and the development of early circuits (for review Sanes and Lichtman, 1999; Schouenborg, 2004; Borodinsky et al., 2012; Blumberg et al., 2013; Spitzer, 2015). In the visual system, spontaneous retinal activity ("retinal waves") triggers cortical activity and controls the formation of retinotopic maps before eye opening (Hanganu et al., 2006; Colonnese and Khazipov, 2010; Colonnese et al., 2010; Ackman et al., 2012; Xu et al., 2015). In the auditory system, spontaneous activity is present in the cochlea at early stages before hearing onset (Tritsch et al., 2007; Johnson et al., 2011; Wang et al., 2015) and controls the development of central auditory pathways. An important role of early spontaneous and evoked activity patterns has been also demonstrated in the developing somatosensory thalamocortical system and it becomes more and more evident that synchronized electrical activity is an important regulator of various ontogenetic processes during earliest stages of sensory system development (for review Hanganu-Opatz, 2010; Kilb et al., 2011; Sieben et al., 2013; Luhmann et al., 2016).

Since spontaneous and evoked activity patterns can be also observed in the cerebral cortex of preterm human babies even before the cortex has gained its 
characteristic six-layered organization (Vanhatalo et al., 2002; Milh et al., 2007; Tolonen et al., 2007; Chipaux et al., 2013; Omidvarnia et al., 2014) (for review Colonnese and Khazipov, 2012), it is also of pivotal clinical interest to understand the mechanisms underlying the generation of early activity patterns and their functional role during early development. The relevance of these questions becomes even more obvious with recent clinical reports demonstrating that fetal antiepileptic drug exposure or exposure to drugs, which are routinely used in neonatal intensive care, have a prominent impact on spontaneous activity (Malk et al., 2014; Videman et al., 2014). Furthermore, increased neuronal activity in preterms correlates with a faster growth of brain structures during subsequent months (Benders et al., 2015) and changes in the pattern of spontaneous activity can be used to predict the clinical outcome of extremely preterm infants (lyer et al., 2015).

The aim of this paper is to provide an overview on our current understanding of the development, the generation and the functional role of early neocortical activity patterns in rodents. Although we will focus on a structurally and functionally well defined subregion of the somatosensory cortex, the barrel cortex (for review Petersen, 2007; Feldmeyer et al., 2013), we will also emphasize the role of subcortical structures and the motor system in the generation of activity patterns in the barrel cortex. Specifically we will address the following questions: (1) What types of spontaneous and evoked activity patterns can be observed in the developing rodent barrel cortex? What do we know about the molecular, cellular and network mechanisms underlying the generation of these different patterns? (2) What is the role of these activity patterns in the formation of early networks and topographic maps? (3) How does electrical activity control programed cell death during early neocortical development?

\section{DEVELOPMENTAL SEQUENCE OF DIFFERENT ACTIVITY PATTERNS IN EARLY NEOCORTICAL DEVELOPMENT}

Many brain structures in different species, in vertebrates as well as in invertebrates, show a similar temporal sequence in the early development of spontaneous and evoked electrical activity patterns. In rodent barrel cortex, four distinct developmental stages can be differentiated depending on the temporal and spatial organization of activity, including its local/large scale and vertical/horizontal synchronization, generative mechanisms, involvement of subcortical and intracortical connections, and physiological functions (Fig. 1). (i) The stage of asynchronous, sparse single-cell firing. (ii) The stage of correlated firing mediated by electrical synapses. (iii) The stage of local bursts driven by early synaptic connections. (iv) The stage of the emergence and maturation of the "adult-like" activity patterns, undergoing experience-dependent modifications during the critical periods of the different sensory systems (for review Khazipov and Luhmann, 2006; Erzurumlu and Gaspar, 2012; Espinosa and Stryker, 2012; Hübener

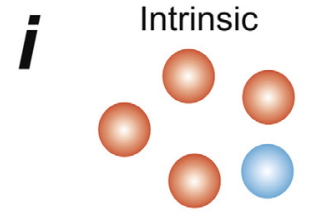

Asynchronous Firing

ii

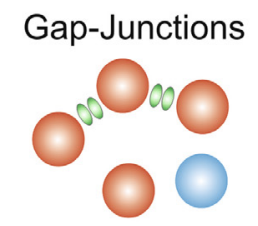

iii

Early Synaptic
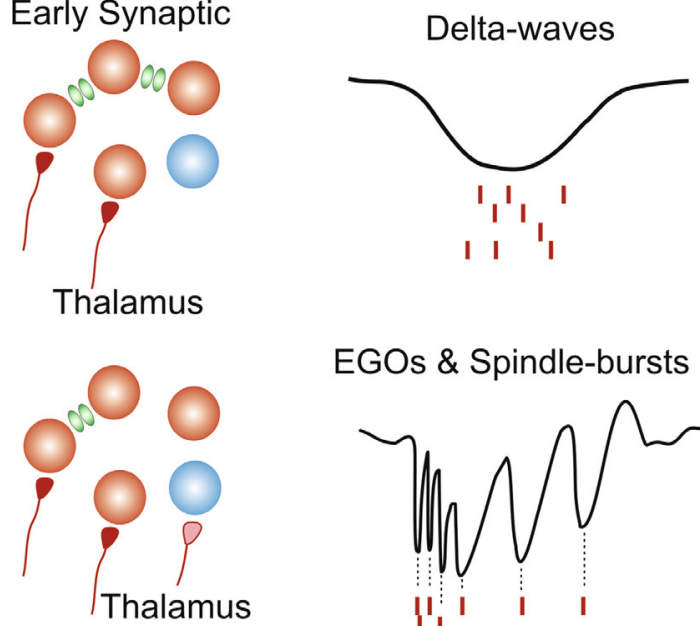

EGOs \& Spindle-bursts
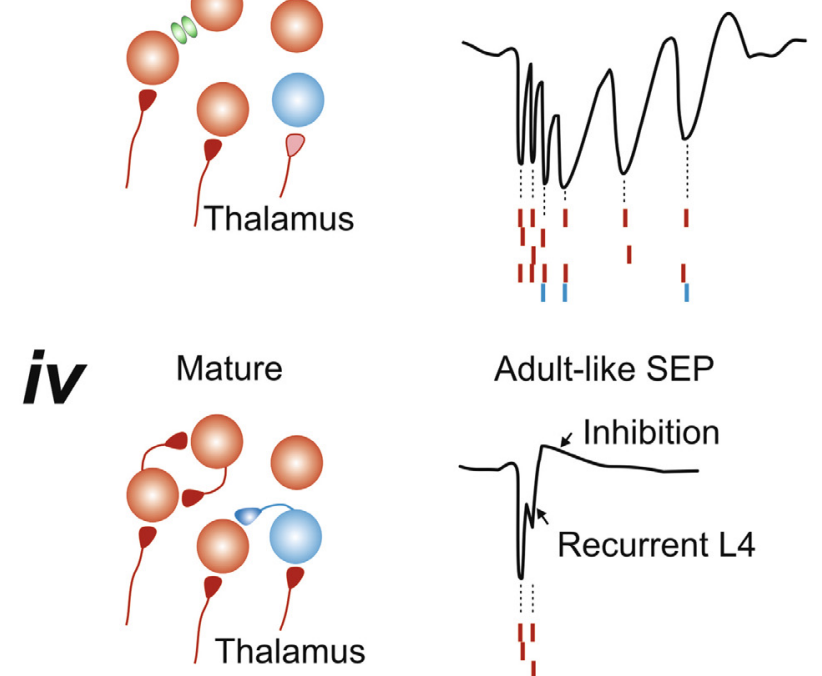

Adult-like SEP

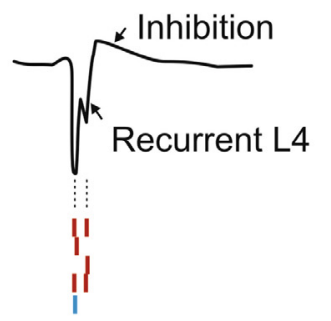

Fig. 1. Sequence of spontaneous and sensory-evoked activity patterns in the developing cerebral cortex. Glutamatergic neurons in red, GABAergic interneurons in blue. (i) Stage of asynchronous, sparse single-cell firing in non-connected neurons. (ii) Stage of correlated firing mediated by electrical synapses. (iii) Stage of local bursts driven by early synaptic connections with thalamocortical and sensory driven inputs. (iv) Emergence and maturation of "adult-like" activity patterns.

and Bonhoeffer, 2014). It has been recently shown that highly synchronized spontaneous calcium waves are present in sensory thalamic nuclei of the mouse already at embryonic day (E) 16.5 (Moreno-Juan et al., 2017). These prenatal thalamic waves propagate among sensory-modality thalamic nuclei and may provide activity-dependent cues to the cortical anlage. Stages iiii in the cerebral cortex are characterized by different spontaneous and sensory-evoked activity patterns and can be considered as "vegetative states". Transition to 
stage iv is marked by an emergence of explorative behaviors, active whisking, and onset of vision and hearing, that has been described in details previously (for review Colonnese and Khazipov, 2012). Since different neuronal elements (nuclei, areas, layers, neurons) may differ in their functional maturation level at a given stage of early development, different activity patterns may be present simultaneously. Here we will give an overview of these four stages in the developing barrel cortex.

\section{(i) The stage of asynchronous, sparse single cell firing}

Before sodium-dependent fast action potentials can be recorded for the first time in developing neocortical neurons of rodents, spontaneous slow intracellular calcium transients can be observed with imaging techniques at embryonic stages (for review Moody and Bosma, 2005; Uhlen et al., 2015). Neurogenesis (Owens and Kriegstein, 1998; Weissman et al., 2004), neuronal migration (Bando et al., 2016) and cellular differentiation (Lohmann et al., 2005) all depend on the spatiotemporal dynamics of intracellular calcium transients. Voltage-dependent sodium and potassium channels gradually appear during embryonic development (Maric et al., 1998) (for review Moody and Bosma, 2005) and at birth (= postnatal day $[P] 0)$ immature pyramidal neurons in rat somatosensory cortex can discharge upon depolarizing current injection only with a few action potentials at low frequency (Luhmann et al., 2000). With further development action potentials become faster and neurons are capable to fire repetitive discharge at higher frequencies. Two distinct transient neuronal populations show relatively mature functional properties already at birth. These are the early generated Cajal-Retzius neurons in the marginal zone/future layer 1 and subplate neurons located at the border to the white matter (for review Luhmann et al., 2009; Kanold and Luhmann, 2010; Luhmann, 2013; Kirischuk et al., 2014). Cajal-Retzius neurons play an important role in the development of the neocortical layering (for review Kilb and Firotscher, 2016) and subplate neurons regulate the correct ingrowth of thalamocortical axons and the formation of cortical columns including barrels (for review Li and Crair, 2011; Hoerder-Suabedissen and Molnar, 2015). Both cell types can fire repetitive action potentials exceeding $30 \mathrm{~Hz}$ and receive synaptic inputs at early stages (for review Luhmann et al., 2014). The functional role of subplate neurons will be discussed in more detail in section ii.

Once glutamatergic pyramidal and GABAergic nonpyramidal neurons have terminated their migration and reached their final position in the developing cerebral cortex (layer 6 to layer 2 according to the inside first outside last ontogenetic pattern), single neurons fire slow action potentials in a random and non-synchronous manner. At this early stage, neurons are mostly isolated and are not connected, neither by electrical nor by chemical synapses. The gradual increase in the number of spiking neurons, firing rate and synchronized burst discharge can be nicely observed and quantified when neurons develop in vitro on multi-electrode arrays (MEAs) (Sun et al., 2010). With the increasing expression of connexins forming electrical synapses between neighboring sparsely firing neurons (for review Elias and Kriegstein, 2008), the first local networks develop and neighboring neurons generate synchronized bursts, which are local and non-propagating. Slow spontaneous calcium transients, which are sensitive to the gap junction blockers octanol and heptanol, have been demonstrated in late embryonic and early postnatal mouse cortex with a clear peak in synchronicity at P0 (Corlew et al., 2004).

\section{(ii) The stage of correlated firing mediated by electrical synapses}

Electrical synapses between excitatory neurons are the first ontogenetic mechanism supporting the earliest forms of correlated neuronal activity during late embryonic and early postnatal age. A bell-shaped developmental profile of the transient coupling via electrical synapses, which mainly connect "sister" cells derived from the same progenitor attains a peak of nearly $40-70 \%$ during the first postnatal week (Connors et al., 1983; Yu et al., 2012; Valiullina et al., 2016). These early electrical synapses are mainly formed by connexin36 containing gap-junctions (Nadarajah et al., 1997; Dupont et al., 2006; Hanganu et al., 2009). Gap junctions between excitatory neurons are eliminated after the first postnatal week and the mode of communication between the excitatory cells switches to chemical (glutamatergic) synapses (Connors et al., 1983; Yu et al., 2012; Valiullina et al., 2016). Lineage-dependent transient electrical coupling between pyramidal cortical neurons appears to guide the formation of excitatory synapses, serving as a template of the intracortical glutamatergic connectivity within an ontogenetic column ( $\mathrm{Yu}$ et al., 2012). However, interneurons seem to follow a different developmental program. Parvalbumin-positive fast spiking (FS) interneurons are initially poorly connected and connections to pyramidal cells (via chemical synapses) and to other FS interneurons (via chemical and electrical synapses) co-develop during the second postnatal week (Yang et al., 2014).

Several correlated activity patterns, synchronized through gap junctions, have been described in slices of the developing cortex in vitro, including correlated calcium waves, neuronal domains, spontaneous plateau assemblies, and carbachol-induced beta oscillations (Yuste et al., 1992; Kandler and Katz, 1998; Peinado, 2000, 2001; Kilb and Luhmann, 2003; Corlew et al., 2004; Dupont et al., 2006; Crepel et al., 2007; Crépel et al., 2007; Allène et al., 2008). One of such patterns emerges in the neocortex and hippocampus at birth in the form of synchronous plateau assemblies (SPAs) (Crépel et al., 2007; Allène et al., 2008). SPAs involve small groups of neurons producing synchronous calcium plateaus associated with sustained intrinsic membrane potential oscillations. Cortical SPAs are not synapse driven since they are not affected by blocking ionotropic glutamate and GABA receptors, but they are in contrast blocked by sodium and L-type calcium channel antagonists. Interestingly, the emergence of SPAs is controlled by signaling molecules involved during delivery since treatment with oxytocin causes an almost twofold 
increase in the fraction of SPA cells (Crépel et al., 2007). The effect of oxytocin on SPAs directly results from the action of the hormone on GABAergic transmission (Tyzio et al., 2006) since SPAs were shown to be favored by an inhibitory GABA polarity, for example produced by NKCC1 blockade (Crépel et al., 2007). Electrical coupling supports not only intermittent SPA-like events, but also oscillatory patterns of synchronized activity in the neonatal cerebral cortex. In the intact in vitro preparation of the immature rodent cerebral cortex cholinergic agonists evoke propagating network oscillations in the beta frequency range (Kilb and Luhmann, 2003). In the newborn mouse, this activity requires an intact subplate and is strongly synchronized within a cortical column by gap junctions. With the developmental disappearance of the subplate at the end of the first postnatal week, activation of NMDA receptors in the immature cortical network is essential to generate this columnar activity pattern (Dupont et al., 2006).

\section{(iii) The stage of local bursts and waves driven by early synaptic connections}

While the earliest cortical activity patterns described above during stages $\mathrm{i}$ and ii have been so far mostly documented in in vitro preparations, subsequent patterns of synchronized activity have been described both in vivo and in vitro. While some of the in vitro activity patterns share certain electrographic and generative network similarity with the in vivo patterns, others do not. Also, some of the in vivo and in vitro patterns may significantly differ in their generative mechanisms despite of a similarity in their electrographic or imaging appearance. Evidently, those patterns that are supported by intracortical circuits should be in theory present both in vitro and in vivo. Yet, it is more problematic to find in a slice preparation a pattern requiring other structures that are not present in the in vitro preparation. Here, we will discuss the in vivo neocortical activity patterns in rodents with a reference to their likely in vitro counterparts.

Delta-waves. The most immature activity pattern observed during the first two days after birth (P0-1) in rodent cerebral cortex, are delta-waves that may occasionally organize in groups of 2-3 successive deltawaves. These early delta-waves often contain rapid oscillatory components consisting of early gamma oscillations (EGOs) and spindle-bursts (Yang et al., 2009,2013 ) or may be "smooth" lacking any rapid oscillatory component (Mitrukhina et al., 2015). Regardless of the presence or absence of the rapid component, the sink of the delta-wave/spindle burst activity is located in the inner layer of the dense cortical plate (future layer 4) and in the subplate (Yang et al., 2009; Mitrukhina et al., 2015). Spontaneous activity is extremely discontinuous at this period. Sensory-evoked responses are characterized by particularly robust refractoriness and virtually all neuronal firing is synchronized in delta-waves (Yang et al., 2009, 2013; Mitrukhina et al., 2015). Whole-cell recordings from cortical neurons revealed that glutamatergic currents are the main driver of the delta-wave activity (Mitrukhina et al., 2015). These glutamatergic currents most likely originate from the thalamus and from the subplate as glutamatergic synapses between $L 4$ neurons are not existent at birth (Valiullina et al., 2016). GABAergic currents during delta-waves are either absent or sparse, reflecting a delayed maturation of neocortical GABAergic circuits (Daw et al., 2007; Minlebaev et al., 2011). Delta waves are also a characteristic fingerprint of the EEG activity in preterm human neonates aged $<25$ gestational weeks, corresponding to the rodent cerebral cortex near term (Higashi et al., 2002; Kostovic and Judas, 2010; Andre et al., 2010).

Sensory-evoked responses are surprisingly ample at birth (Yang et al., 2009, 2013; Mitrukhina et al., 2015), despite the fact that the initial thalamocortical synapses are weak and limited in number, and that their vast majority are pure NMDA-receptor-based "silent" synapses at resting membrane potential (for review Feldman et al., 1999; Hanse et al., 2013). Generation of such robust responses at birth likely involves powerful temporal summation of slow NMDA and kainate receptor-mediated currents at the immature thalamocortical synapses (Kidd and Isaac, 1999; Minlebaev et al., 2007, 2009b; Hirsch and Luhmann, 2008), which elicit extensive depolarization in immature neurons, with very high (in the gigaohms range) membrane resistance (LoTurco et al., 1991; Luhmann et al., 2000; Valiullina et al., 2016). Another factor contributing to robust responses at birth is a lack of feedforward inhibition and large (indefinite in cells lacking GABAergic inputs) temporal window for integration of excitatory inputs (Daw et al., 2007; Minlebaev et al., 2011).

In terms of spatial organization, the activity in barrel cortex at birth shows a remarkable level of topographic organization of the whisker-related somatosensory maps well before the anatomical barrels are formed at around P3. During this pre-barrel epoch, which is also a critical period of the "anatomical" plasticity in the barrel cortex, stimulation of a single whisker evokes a delta-wave/ spindle burst, a prominent voltage-sensitive dye (VSD) response, neuronal firing and polysynaptic, mainly glutamate receptor mediated currents during whole-cell recordings (Yang et al., 2013; Mitrukhina et al., 2015). At this age single whisker stimulation elicits mostly a local response in one or two columnar networks as revealed by VSD imaging and multi-electrode array recording (Yang et al., 2013), demonstrating the existence of a topographic and columnar representation in the rodent barrel cortex already at birth.

This innate protomap is refined during the first postnatal days through an improvement in the topographic precision of the cortical projection fields of a single whisker and of the receptive fields of cortical neurons (Mitrukhina et al., 2015). This functional refinement of the protomap during the first 2-3 days after birth coincides with the formation of anatomical barrels including maturation and segregation of their pre- and postsynaptic elements. At the presynaptic level, formation of the barrel pattern by the thalamocortical axons organized into barrel-shaped bundles in layer 4 occurs between P2 and P4 (Erzurumlu and Jhaveri, 1990; Agmon et al., 
1995). At the postsynaptic level, cytoarchitectonic barrel formation and the differentiation of layer 4 start at around P3 (Rice, 1985; Jhaveri et al., 1991; Blue et al., 1991). Layer 4 cells of the barrel cortex do not show dendritic orientation at birth. During the first postnatal week dendrites gradually orient themselves around the thalamocortical terminal patches, accompanied by NMDA-receptordependent pruning of the dendritic branches extending to neighboring barrels (Espinosa et al., 2009). In addition, feedforward inhibition, which sets a temporal window of integration of thalamic inputs and contributes to surround inhibition, is absent during the first postnatal days (Daw et al., 2007; Minlebaev et al., 2011). Finally, a large number of pure NMDA receptor-based "silent" thalamocortical synapses (for review Feldman et al., 1999; Hanse et al., 2013), in conjunction with the high affinity of NMDA-Rs to glutamate (Patneau and Mayer, 1990) and a large extracellular space (Thomas et al., 2011), may lead to spill-over and paracrine actions of glutamate released from thalamic axons and growth cones at distant sites (for review Kullmann and Asztely, 1998). All of the above anatomical and functional properties are subject to rapid developmental changes contributing to the refinement of the innate protomap during the first postnatal days.

The functional investigation of the spatial organization of activity in the neonatal barrel cortex indicates that development of the barrel map involves initial formation of the basic protomap at around birth via innate mechanisms followed by its activity-dependent refinement (Rakic, 1976) (for review Katz and Shatz, 1996; López-Bendito and Molnár, 2003; O’Leary and Sahara, 2008; Rakic et al., 2009; Erzurumlu and Gaspar, 2012). Refinement of the barrel map precision during the first 2 to 3 postnatal days is characterized by competitive interactions between whiskers for their cortical territories through early activity patterns, that may be instrumental for the barrel map refinement. Once somatotopic correspondence is established by P2-P3, topographic thalamocortical synapses may further mature through synaptic plasticity supported by the rapid oscillatory patterns.

In slices of somatosensory cortex in vitro, cortical early network oscillations (cENOs) represent a synaptically organized activity pattern expressed during the first days after birth (Garaschuk et al., 2000; Corlew et al., 2004; McCabe et al., 2006; Allène et al., 2008). cENOs are low-frequency oscillations $(\sim 0.01 \mathrm{~Hz})$ displaying slow kinetics that gradually involve the entire network regardless of the anatomical boundaries between the structures. cENOs involve activation of NMDA receptors at intracortical synapses, but also extrasynaptic NMDA receptors activated by glutamate spill-over or its release from growth cones. cENOs in vitro and delta waves in vivo both primarily involve glutamatergic mechanisms in their generation. However, these two patterns differ in the spatiotemporal dynamics and in the origin of the glutamatergic synapses - corticocortical in the case of cENOs and thalamocortical in the case of the delta waves. Surprisingly, neither early delta waves nor EGOs and spindle bursts are observed in neonatal thalamocortical slices despite the preserved integrity between the bar- reloids and barrels and an ability of this preparation generating sleep spindle-like events later in development (McCormick et al., 1995; Warren and Jones, 1997; Evrard and Ropert, 2009).

EGOs and spindle bursts. The dominant in vivo oscillatory activity patterns in the barrel cortex during neonatal development are spatially confined spindle bursts and EGOs (for review Khazipov et al., 2013; Blumberg et al., 2013; Cirelli and Tononi, 2015; Yang et al., 2016; Luhmann et al., 2016; Luhmann, 2017) (Fig. 2). Spindle bursts are local network oscillations in a frequency range of $5-25 \mathrm{~Hz}$ and with a duration of $0.5-3 \mathrm{~s}$. They can be elicited by whisker stimulation or appear spontaneously every $\sim 10 \mathrm{~s}$ (Khazipov et al., 2004; Minlebaev et al., 2007; Yang et al., 2009). Kummer et al. (2016) recently demonstrated with threedimensional two-photon calcium imaging in P3-P4 mouse visual cortex in vivo that spindle bursts represent the electrophysiological correlate of a local columnar network. The second prominent pattern in the barrel cortex (and other neocortical areas) of neonatal rodents are local EGOs in a frequency range of $30-50 \mathrm{~Hz}$ and with a duration of $100-300 \mathrm{~ms}$. These two oscillatory patterns may co-exist within a given activity burst, but they may also occur independently (Fig. 2A, B). During sensory evoked responses, the activity bursts typically start with EGOs and end with spindle burst (Fig. 2C). Also, troughs of spindle bursts may nest few EGO cycles. Whole-cell patchclamp recordings from different neuronal populations in newborn mouse S1 cortex in vitro and analyzing their responsiveness to sinusoidal current injection of varying frequency could not reveal any intrinsic membrane resonance to the typical frequencies of spindle bursts and EGOs (Sun et al., 2012, 2014). These data indicate that both activity patterns result from network interactions.

There are many similarities between these two oscillatory patterns suggesting a mechanistic link between them. EGOs and spindle bursts are nested in a delta-wave during DC recordings (Marcano-Reik and Blumberg, 2008; Minlebaev et al., 2009a). Current source density analysis indicates maximal sinks of both oscillations located in layer 4 suggesting thalamic involvement. Also, both are triggered by thalamic stimulation and are completely suppressed by thalamic ablation (Yang et al., 2013). Although both patterns are local, spindle bursts tend to activate larger cortical territories (200$400 \mu \mathrm{m}$ ) than EGOs, that are mostly located in one barrel-related column ( $200 \mu \mathrm{m})$ (Yang et al., 2009). EGOs and spindle bursts are developmentally transient activity patterns that disappear in barrel cortex at around P7-P8 (Colonnese et al., 2010). Between P0 and P3 spindle bursts require electrical synapses, probably via connexin-36 containing gap junctions (Dupont et al., 2006). With further development spindle bursts and EGOs are primarily dependent on glutamatergic synaptic transmission and they are completely suppressed by the application of ionotropic glutamate receptor antagonists (Dupont et al., 2006; Minlebaev et al., 2007). At the cellular level, glutamatergic currents are the main drivers of EGOs and spindle burst oscillations whereas GABAergic 

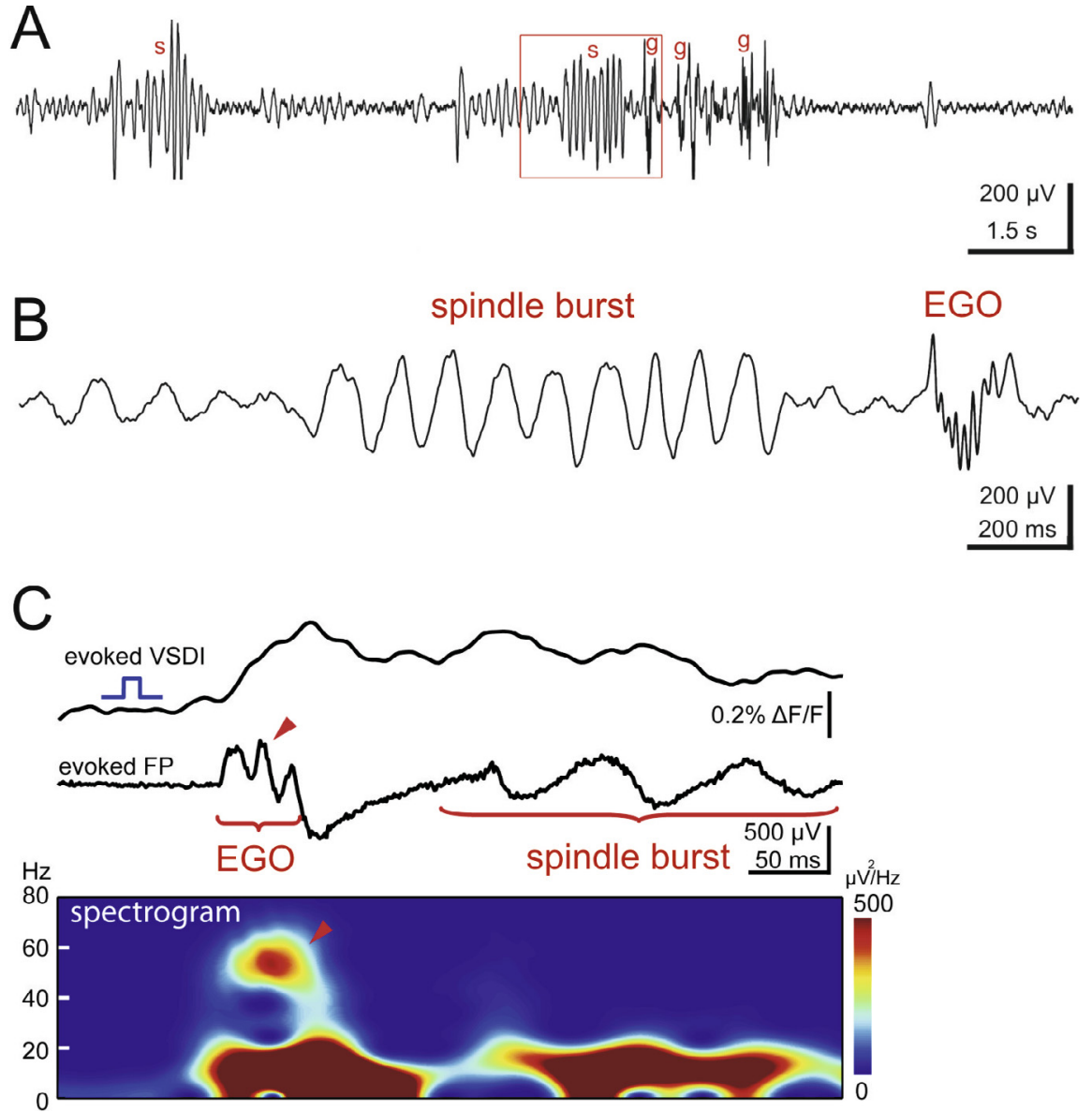

Fig. 2. Prominent activity patterns in barrel cortex of newborn rodents in vivo. (A) Field potential recording in a P3 rat displaying spindle burst activity (s) and EGOs (g). (B) Spindle burst and EGO shown at expanded timescale (see red box in A). (C) Simultaneous voltage-sensitive dye imaging (VSDI) and local field potential (FP) response to single mechanical whisker stimulation recorded in barrel cortex of a P1 rat. Wavelet spectogram of the FP response below shows gamma component at $50-60-\mathrm{Hz}$ and $10-20-\mathrm{Hz}$ spindle activity. A, B from (Yang et al., 2009), C from (Yang et al., 2013).

synaptic currents show age-dependent involvement (Minlebaev et al., 2007, 2009a,b, 2011; Mitrukhina et al., 2015). Both patterns are internally generated patterns persisting after sensory deprivation, although their occurrence is reduced after deprivation (Khazipov et al., 2004; Yang et al., 2009; Akhmetshina et al., 2016). During whisker stimulation, EGOs are best observed after a brief deflection of a single principal whisker but they are less prominent during responses evoked by stimulation of multiple whiskers, during which spindle bursts dominate the activity (Minlebaev et al., 2007, 2009b; Colonnese et al., 2010). EGOs have generative mechanisms that cardinally differ from adult gamma oscillations (for reviewed Khazipov et al., 2013; Luhmann et al., 2016). While adult gamma oscillations are generated through gammarhythmic perisomatic inhibition (for review Wang, 2010), EGOs in newborn rodent cerebral cortex are primarily driven through feedforward gamma-rhythmic excitatory input from the thalamus (Minlebaev et al., 2011; Yang et al., 2013), a mechanism recently attributed to the narrow band gamma oscillations in adult visual cortex (Saleem et al., 2017). The recruitment of cortical interneurons to EGOs was observed by the end of the first postnatal week along with the emergence of feedforward inhibition (Daw et al., 2007; Minlebaev et al., 2011).

Network mechanisms of spindle burst generation are less well understood. There are several arguments to argue that spindle bursts are generated differently than sleep spindles in adults. Firstly, sleep spindle-like events are not observed in thalamic slices of mice until P12 and ferrets until P33 (McCormick et al., 1995; Warren and Jones, 1997). Secondly, in human neonates, there is a two-month gap between delta-brushes (a human homologue of the spindle bursts), which disappear at around term and sleep spindles, which emerge one to two months after birth (Ellingson, 1982; Andre et al., 2010). Finally, sleep spindles are synchronized over large territories through intracortical and corticothalamic connections (Contreras et al., 1996, 1997) whereas spindle bursts are local events. Thus, the generation of spindle bursts in neonatal cortex is probably mechanistically different from the sleep spindles in adult cortex, but the exact mechanisms remain to be elucidated. While EGOs are not reproduced in any in vitro model and do not match any existing in vitro pattern of the early synchronized activity, spindle bursts show some electrographic and pharmacological similarity with the carbachol induced NMDA receptor-dependent beta oscillations in the intact neonatal cortex in vitro (Kilb and Luhmann, 2003; Dupont et al., 2006; Minlebaev et al., 2007), suggesting the involvement of a similar circuit. This is also in agreement with the muscarinic cholinergic modulation of spindle bursts in barrel cortex (Hanganu et al., 2009) as well as in the visual cortex (Hanganu et al., 2007). As mentioned above, EGOs and spindle bursts persist after sensory deprivation. However, both activity patterns are reliably evoked by external sensory stimulation and by sensory feedback from self-generated whisker movements. While rapid active whisking starts together with explorative behavior at around P12 (Landers and Philip, 2006; Grant et al., 2012) a wide diversity of other whisker and mystacial pad movement patterns exist during neonatal period (Tiriac et al., 2012; Akhmetshina et al., 2016). Although the origin of these spontaneous whisker movements is at present unknown, it may involve spontaneous activity of the follicular complex under control of brainstem and motor cortex as described in skeletal muscles (Khazipov et al., 2004; Nguyen et al., 2004; An et al., 2014; Rio-Bermudez et al., 2015; Inacio et al., 2016) (for review Luhmann et al., 2016). Similar to adult animals 
(Bermejo et al., 2002; Hill et al., 2008), whisker movements in neonatal rat pups are characterized by the predominance of collective movements with the maximal movement correlations between adjacent whiskers in a row, and with the preferred movement directions of protraction and retraction (Akhmetshina et al., 2016). Free whisker movements were shown to elevate thalamic VPM and barrel cortical activity indicating that reafferent sensory feedback acts as an efficient sensory signal (Tiriac et al., 2012; Yang et al., 2013; Akhmetshina et al., 2016) similar to the body twitches evoking spindle bursts in the S1 body regions (Khazipov et al., 2004). However this is different from the results obtained in adult animals, where free whisking, associated with the induction of the neocortical active state, did not alter the average firing frequency of principal neurons (Crochet and Petersen, 2006; Poulet and Petersen, 2008). The difference is likely due to the delayed development of the active states (Colonnese et al., 2010) and inhibitory intracortical mechanisms (Fagiolini et al., 2004; Daw et al., 2007; Minlebaev et al., 2011; Colonnese, 2014). Yet, cortical unit activation and an increase in spindle and gamma bursts local field potential power during whisker movements was significantly stronger if the whisker is touching an external object during movement (Akhmetshina et al., 2016). This is consistent with the findings made in adult animals, where presenting an object into the whisking path was shown to increase the number of responsive neurons in the trigeminal ganglion (Zucker and Welker, 1969; Szwed et al., 2003) and to increase the firing of neurons in the barrel cortex (Crochet et al., 2011).

Under conditions mimicking natural environment spontaneous whisker movements and passive stimulation by the littermates were shown to cooperate, with comparable efficiency, in driving cortical activity (Akhmetshina et al., 2016). Comparison of the various experimental conditions mimicking the natural environment showed that tactile signals arising from the whisker movements with touch and stimulation by the littermates support (i) a twofold higher level of cortical activity than in the isolated animal, and (ii) a threefold higher level of activity than in the deafferented animal after infraorbital nerve cut (Akhmetshina et al., 2016). This indicates that endogenous (self-generated movements) and exogenous (stimulation by the littermates) mechanisms cooperate in driving activity in barrel cortex of newborn rats and point to the importance of the environment in shaping cortical activity during the neonatal period. While barrel cortex (and somatosensory system in general) possesses endogenous and exogenous mechanisms for sensory stimulation, development of visual and auditory systems relies only on the endogenous mechanisms, based on spontaneous activity at the sensory periphery - retinal waves and cochlear bursts -when the animals are deaf and blind during the neonatal period.

The subplate, a transient neocortical layer between layer 6 and the white matter (for review Kanold and Luhmann, 2010), plays an important role in the generation of spindle bursts in newborn rodent barrel cortex and selective removal of the subplate abolishes spindle bursts (Dupont et al., 2006) and prevents the development of the characteristic histological barrel-like appearance (Tolner et al., 2012). These data indicate that spindle bursts play a pivotal role in the structural and functional maturation of the cerebral cortex. Since spindle burst (delta brush) activity is also a physiological hallmark of the developing human cerebral cortex during preterm and neonatal stages (Nevalainen et al., 2015; Koolen et al., 2016) (for review Khazipov and Luhmann, 2006), it can be assumed that any disturbances in spindle burst activity during corticogenesis may cause developmental disorders associated with neurological or cognitive deficits.

\section{(iv) The stage of the emergence and maturation of the "adult-like" activity patterns}

Neonatal activity patterns of spindle bursts and EGOs are transient physiological patterns that disappear in barrel cortex at around P7-P8, together with a developmental switch in the sensory-evoked responses from EGO/ spindle-bursts to adult-like brief and short-latency responses (Colonnese et al., 2010; Minlebaev et al., 2011). This sharp change in the operation mode of the barrel cortex includes an emergence of continuous cortical background activity and adult-like activity patterns, modulation of activity by the behavioral states and horizontal spread of the activity (for review Colonnese and Khazipov, 2012). This is also associated with an emergence of the explorative behaviors and rapid whisking which starts at around P12 (van der Bourg et al., 2016). In a recent study van der Bourg et al. have demonstrated by the use of multi-electrode recordings and 2-photon calcium imaging in anesthetized P10-P28 mice several layer-specific developmental changes in the responses to axial or lateral whisker stimulation (van der Bourg et al., 2016). (i) Sensory-evoked responses decreased with age in layer 2/3 and layer 4, whereas they increased in infragranular layers. (ii) Upper and lower layers also revealed a different developmental profile to neuronal adaptation during a 2-s stimulation at $\sim 5 \mathrm{~Hz}$. Whereas layers $2 / 3$ showed facilitation before the critical period, which then turned into slight depression, lower layers showed the opposite trend with prominent adaptation before P14, which got weaker with age. At around P14 evoked responses in upper layers were characterized by a progressive sparsification and decorrelation (van der Bourg et al., 2016), similar as observed previously in layer 2/3 of mouse barrel cortex (Golshani et al., 2009) and visual cortex after eye opening (Rochefort et al., 2009). All these data demonstrate for developing mouse barrel cortex a pronounced layer-specific functional reorganization in a short time-window at the onset of active whisking behavior.

\section{ROLE OF EARLY ACTIVITY IN NETWORK FUNCTION AND FORMATION}

A compelling amount of experimental data indicates that early activity plays an important role in the development of functional connectivity, topographic maps and higherorder associative circuits (for review Kirkby et al., 2013; Ackman and Crair, 2014; Okawa et al., 2014). In the developing visual system it has been documented that 
early neuronal activity interacts with transcriptional gene regulation to control network formation (for review Cang and Feldheim, 2013). The activity-dependent development of the barrel cortex has been reviewed by Erzurumlu and Gaspar (2012) and here we will focus on the specific role of the two prominent patterns in the developing barrel cortex, the spindle bursts and the EGOs. In agreement with the important role of the subplate in generating spindle bursts in the neonatal barrel cortex, Tolner et al. (2012) demonstrated that selective removal of the subplate eliminates spontaneous and sensory evoked spindle bursts and prevents the normal formation of barrels. These data suggest that spindle burst activity directly influences the development of the cortical architecture. Further support for this hypothesis comes from experimental studies on newborn rats after induction of a hypoxic-ischemic brain injury. Early brain injury causes a loss of spindle burst activity associated with an impaired dendrite and spine development and a decreased barrel cortex structural plasticity after whisker removal (Ranasinghe et al., 2015).

It has been further suggested that EGOs provide ideal conditions for the activity-dependent potentiation of thalamocortical connections and the formation of topographic connectivity (for review Khazipov et al., 2013). Each cycle of a gamma oscillation elicits an action potential in the neocortical layer 4 spiny stellate cell shortly after the firing of the presynaptic thalamic neuron, thereby providing an ideal condition of Hebbian synaptic potentiation. In contrast non-topographic connections will be weakened.

Spindle bursts and EGOs are also ideal activity patterns to trigger movements and to activate via feedback circuits the somatosensory cortex in newborn rodents. Local electrical stimulation in layer 5 of the primary motor cortex of a neonatal rat preferentially elicits movements when the stimulation frequency is $10 \mathrm{~Hz}$ (spindle burst activity) or $40 \mathrm{~Hz}$ (EGO), which subsequently evokes spindle bursts and EGOs in the somatosensory cortex (An et al., 2014). Newborn rats show spontaneous whisker movements during active sleep and the large majority of these twitches elicit activity in the barrel cortex (Tiriac et al., 2012). Synchronized spontaneous activity in motor and sensory networks already occur in the spinal cord of newborn rats (Inacio et al., 2016) and these early burst patterns may be of central importance for the activity-dependent development of topographic connections between the motor and the somatosensory system in supraspinal regions including the cerebral cortex (for review Luhmann et al., 2016).

\section{ROLE OF EARLY ACTIVITY IN CONTROLLING APOPTOSIS}

Programed cell death (apoptosis) is an important process during early brain development (for review Fuchs and Steller, 2011). In the cerebral cortex of rodents, about $70 \%$ of the neurons die by apoptosis around E14 (Blaschke et al., 1996). A second wave of apoptosis can be observed during the first postnatal week (for review Nikolic et al., 2013), exactly during a developmental per- iod when the cerebral cortex reveals a rich repertoire of spontaneous and evoked synchronized activity patterns. It is therefore not surprising that any disturbance in these early activity patterns has a strong impact on the control of programed cell death. Electrical activity controls cell survival versus cell death. In vitro studies in organotyopic slice cultures of the developing rodent somatosensory cortex have demonstrated that blockade of electrical activity by application of tetrodotoxin (TTX) for only $6 \mathrm{~h}$ causes an increase in naturally occurring neuronal death by a factor of $\sim 2.5$ (Heck et al., 2008). Neuropharmacological studies uncovered the upstream and downstream mechanisms of this activity-dependent regulation of apoptosis during the first postnatal week of neocortical development. NMDA receptors, L-type voltage-dependent calcium channels and the tropomyosin-related kinase (Trk) receptor B/C play central roles in the activitydependent control of apoptosis (Heck et al., 2008). Synchronized burst discharges with frequencies of 20$50 \mathrm{~Hz}$ appearing every $\sim 20 \mathrm{~s}$ are most effective to trigger the release of brain-derived neurotrophic factor (BDNF) (Balkowiec and Katz, 2000), which activates TrK B/C receptors for survival (for review Lessmann et al., 2003). In addition GABA-A receptors and electrical synapses influence programed cell death (for review Kilb et al., 2011). The downstream pathway for cell survival involves the phosphatidylinositol 3-kinase/Akt pathway, controlling cAMP response element-binding (CREB) protein and nuclear factor kappa-light-chainenhancer of activated B-cells (NF-kappaB) (WagnerGolbs and Luhmann, 2012).

Combining quantitative measurements of neuronal apoptosis with in vitro multi-electrode array recordings revealed that synchronized network bursts are necessary and sufficient to promote neuronal survival and to prevent elevated apoptosis (Golbs et al., 2011). These in vitro observations indicate that spindle bursts and EGOs are physiologically relevant activity patterns to regulate cell survival versus cell death in the developing cerebral cortex. Support for this hypothesis comes from in vivo experiments demonstrating that inflammationinduced modifications in the properties of spontaneous spindle bursts and EGOs cause a rapid increase in caspase-3 mediated neuronal death (Nimmervoll et al., 2013).

These data strongly suggest that the physiological activity patterns spindle bursts and EGOs are particularly suited to suppress apoptosis. From that we can conclude that any disturbance in these spontaneous activity patterns during early development will interfere with programed cell death. Since spindle bursts and EGOs are controlled by various mechanisms, a variety of drugs modify these patterns and thereby may induce pathological alterations in programed cell death in vivo. Application of alcohol, a non-competitive inhibitor of NMDA receptors, to $\mathrm{P} 4-7$ rats in vivo causes a dosedependent suppression of spontaneous and sensoryevoked spindle bursts and EGOs and massive neuronal apoptosis (Lebedeva et al., 2015). The anesthetics ketamine and midazolam also modify spontaneous activity in S1 of newborn rats (Lebedeva et al., 2016) and it has 
been well documented that general anesthetics induce widespread neuronal cell death in the developing cortex causing long-lasting cognitive and behavioral deficits, both in experimental animal studies as well as in clinical reports (for review McCann et al., 2009; Istaphanous and Loepke, 2009; Lee et al., 2015). Other compounds modifying early neuronal activity patterns are antiepileptic drugs, which also cause neuronal apoptosis in the developing brain (for review Ikonomidou and Turski, 2010).

\section{PERSPECTIVES}

Although distinct neuronal activity patterns have been demonstrated in newborn rodent barrel cortex with various techniques under in vitro and in vivo conditions, neither their underlying mechanisms nor their functional role during early neocortical development are fully understood. It became clear that subcortical structures, other cortical areas and motor systems play a central role in the generation of certain activity patterns. It became also evident that early cortical activity patterns are not only epiphenomena of developing neuronal circuits, but rather that they play distinct roles in neocortical maturation. It remains to be elucidated if and how specific activity frequencies shape specific developmental processes.

Acknowledgments-The authors are most thankful to their coworkers who contributed over the last years to the results discussed in this review. Financial support for our work came from the Deutsche Forschungsgemeinschaft (H.J.L.), INSERM and the program of competitive growth of KFU (R.K.).

\section{REFERENCES}

Ackman JB, Burbridge TJ, Crair MC (2012) Retinal waves coordinate patterned activity throughout the developing visual system. Nature 490:219-225.

Ackman JB, Crair MC (2014) Role of emergent neural activity in visual map development. Curr Opin Neurobiol 24:166-175.

Agmon A, Yang LT, Jones EG, O'Dowd DK (1995) Topological precision in the thalamic projection to neonatal mouse barrel cortex. J Neurosci 15:549-561.

Akhmetshina D, Nasretdinov A, Zakharov A, Valeeva G, Khazipov R (2016) The Nature of the Sensory Input to the Neonatal Rat Barrel Cortex. J Neurosci 36:9922-9932.

Allène C, Cattani A, Ackman JB, Bonifazi P, Aniksztejn L, Ben-Ari Y, Cossart R (2008) Sequential generation of two distinct synapsedriven network patterns in developing neocortex. J Neurosci 28:12851-12863.

An S, Kilb W, Luhmann HJ (2014) Sensory-evoked and spontaneous gamma and spindle bursts in neonatal rat motor cortex. J Neuroscience 34:10870-10883.

Andre M, Lamblin MD, d'Allest AM, Curzi-Dascalova L, MoussalliSalefranque F, The SN, Vecchierini-Blineau MF, Wallois F, WallsEsquivel E, Plouin P (2010) Electroencephalography in premature and full-term infants. Developmental features and glossary. Neurophysiol Clin 40:59-124.

Balkowiec A, Katz DM (2000) Activity-dependent release of endogenous brain-derived neurotrophic factor from primary sensory neurons detected by ELISA in situ. J Neurosci 20:7417-7423.

Bando Y, Irie K, Shimomura T, Umeshima H, Kushida Y, Kengaku M, Fujiyoshi Y, Hirano T, Tagawa Y (2016) Control of spontaneous
$\mathrm{Ca} 2+$ transients is critical for neuronal maturation in the developing neocortex. Cereb Cortex 26:106-117.

Benders MJ, Palmu K, Menache C, Borradori-Tolsa C, Lazeyras F, Sizonenko S, Dubois J, Vanhatalo S, Huppi PS (2015) Early brain activity relates to subsequent brain growth in premature infants. Cereb Cortex 25:3014-3024.

Bermejo R, Vyas A, Zeigler HP (2002) Topography of rodent whisking - I. Two-dimensional monitoring of whisker movements. Somatosens Mot Res 19:341-346.

Blankenship AG, Feller MB (2010) Mechanisms underlying spontaneous patterned activity in developing neural circuits. Nat Rev Neurosci 11:18-29.

Blaschke AJ, Staley K, Chun J (1996) Widespread programmed cell death in proliferative and postmitotic regions of the fetal cerebral cortex. Development 122:1165-1174.

Blue ME, Erzurumlu RS, Jhaveri S (1991) A comparison of pattern formation by thalamocortical and serotonergic afferents in the rat barrel field cortex. Cereb Cortex 1:380-389.

Blumberg MS, Marques HG, lida F (2013) Twitching in sensorimotor development from sleeping rats to robots. Curr Biol 23: R532-R537.

Borodinsky LN, Belgacem YH, Swapna I (2012) Electrical activity as a developmental regulator in the formation of spinal cord circuits. Curr Opin Neurobiol 22:624-630.

Cang J, Feldheim DA (2013) Developmental mechanisms of topographic map formation and alignment. Annu Rev Neurosci 36:51-77.

Chipaux M, Colonnese MT, Mauguen A, Fellous L, Mokhtari M, Lezcano O, Milh M, Dulac O, Chiron C, Khazipov R, Kaminska A (2013) Auditory stimuli mimicking ambient sounds drive temporal "delta-brushes" in premature infants. PLoS One 8.

Cirelli C, Tononi G (2015) Cortical development, electroencephalogram rhythms, and the sleep/wake cycle. Biol Psychiatry 77:1071-1078.

Colonnese M, Khazipov R (2012) Spontaneous activity in developing sensory circuits: Implications for resting state fMRI. Neuroimage 62:2212-2221.

Colonnese MT (2014) Rapid developmental emergence of stable depolarization during wakefulness by inhibitory balancing of cortical network excitability. J Neurosci 34:5477-5485.

Colonnese MT, Kaminska A, Minlebaev M, Milh M, Bloem B, Lescure S, Moriette G, Chiron C, Ben-Ari Y, Khazipov R (2010) A conserved switch in sensory processing prepares developing neocortex for vision. Neuron 67:480-498.

Colonnese MT, Khazipov R (2010) "Slow activity transients" in infant rat visual cortex: a spreading synchronous oscillation patterned by retinal waves. J Neurosci 30:4325-4337.

Connors BW, Bernardo LS, Prince DA (1983) Coupling between neurons of the developing rat neocortex. J Neurosci 3:773-782.

Contreras D, Destexhe A, Sejnowski TJ, Steriade M (1996) Control of spatiotemporal coherence of a thalamic oscillation by corticothalamic feedback. Science 274:771-774.

Contreras D, Destexhe A, Sejnowski TJ, Steriade M (1997) Spatiotemporal patterns of spindle oscillations in cortex and thalamus. J Neurosci 17:1179-1196.

Corlew R, Bosma MM, Moody WJ (2004) Spontaneous, synchronous electrical activity in neonatal mouse cortical neurons. J Physiol 560:377-390.

Crepel V, Aronov D, Jorquera I, Represa A, Ben Ari Y, Cossart R (2007) A parturition-associated nonsynaptic coherent activity pattern in the developing hippocampus. Neuron 54:105-120.

Crépel V, Aronov D, Jorquera I, Represa A, Ben-Ari Y, Cossart R (2007) A parturition-associated nonsynaptic coherent activity pattern in the developing hippocampus. Neuron 54:105-120.

Crochet S, Petersen CC (2006) Correlating whisker behavior with membrane potential in barrel cortex of awake mice. Nat Neurosci 9:608-610.

Crochet S, Poulet JFA, Kremer Y, Petersen CCH (2011) Synaptic mechanisms underlying sparse coding of active touch. Neuron 69:1160-1175. 
Daw MI, Ashby MC, Isaac JT (2007) Coordinated developmental recruitment of latent fast spiking interneurons in layer IV barrel cortex. Nat Neurosci 10:453-461.

Dupont E, Hanganu IL, Kilb W, Hirsch S, Luhmann HJ (2006) Rapid developmental switch in the mechanisms driving early cortical columnar networks. Nature 439:79-83.

Elias LA, Kriegstein AR (2008) Gap junctions: multifaceted regulators of embryonic cortical development. Trends Neurosci 31:243-250.

Ellingson RJ (1982) Development of sleep spindle bursts during the first year of life. Sleep 5:39-46.

Erzurumlu RS, Gaspar P (2012) Development and critical period plasticity of the barrel cortex. Eur J Neurosci 35:1540-1553.

Erzurumlu RS, Jhaveri S (1990) Thalamic axons confer a blueprint of the sensory periphery onto the developing rat somatosensory cortex. Dev Brain Res 56:229-234.

Espinosa JS, Wheeler DG, Tsien RW, Luo L (2009) Uncoupling dendrite growth and patterning: single-cell knockout analysis of NMDA receptor 2B. Neuron 62:205-217.

Espinosa JS, Stryker MP (2012) Development and plasticity of the primary visual cortex. Neuron 75:230-249.

Evrard A, Ropert N (2009) Early development of the thalamic inhibitory feedback loop in the primary somatosensory system of the newborn mice. J Neurosci 29:9930-9940.

Fagiolini M, Fritschy JM, Löw K, Möhler H, Rudolph U, Hensch TK (2004) Specific GABA-A circuits for visual cortical plasticity. Science 303:1681-1683.

Feldman DE, Nicoll RA, Malenka RC (1999) Synaptic plasticity at thalamocortical synapses in developing rat somatosensory cortex: LTP, LTD, and silent synapses. J Neurobiol 41:92-101.

Feldmeyer D, Brecht M, Helmchen F, Petersen CCH, Poulet JFA, Staiger JF, Luhmann HJ, Schwarz C (2013) Barrel cortex function. Prog Neurobiol 103:3-27.

Feller MB, Scanziani M (2005) A precritical period for plasticity in visual cortex. Curr Opin Neurobiol 15:94-100.

Fuchs Y, Steller H (2011) Programmed cell death in animal development and disease. Cell 147:742-758.

Garaschuk O, Linn J, Eilers J, Konnerth A (2000) Large-scale oscillatory calcium waves in the immature cortex. Nat Neurosci 3:452-459.

Golbs A, Nimmervoll B, Sun JJ, Sava IE, Luhmann HJ (2011) Control of programmed cell death by distinct electrical activity patterns. Cereb Cortex 21:1192-1202.

Golshani P, Goncalves JT, Khoshkhoo S, Mostany R, Smirnakis S, Portera-Cailliau C (2009) Internally mediated developmental desynchronization of neocortical network activity. J Neurosci 29:10890-10899.

Grant RA, Mitchinson B, Prescott TJ (2012) The development of whisker control in rats in relation to locomotion. Dev Psychobiol 54:151-168

Hanganu IL, Ben-Ari Y, Khazipov R (2006) Retinal waves trigger spindle bursts in the neonatal rat visual cortex. J Neurosci 26:6728-6736.

Hanganu IL, Okabe A, Lessmann V, Luhmann HJ (2009) Cellular mechanisms of subplate-driven and cholinergic input-dependent network activity in the neonatal rat somatosensory cortex. Cereb Cortex 19:89-105.

Hanganu IL, Staiger JF, Ben-Ari Y, Khazipov R (2007) Cholinergic modulation of spindle bursts in the neonatal rat visual cortex in vivo. J Neurosci 27:5694-5705.

Hanganu-Opatz IL (2010) Between molecules and experience: role of early patterns of coordinated activity for the development of cortical maps and sensory abilities. Brain Res Rev 64:160-176.

Hanse E, Seth H, Riebe I (2013) AMPA-silent synapses in brain development and pathology. Nat Rev Neurosci 14:839-850.

Heck N, Golbs A, Riedemann T, Sun JJ, Lessmann V, Luhmann HJ (2008) Activity-dependent regulation of neuronal apoptosis in neonatal mouse cerebral cortex. Cereb Cortex 18:1335-1349.

Higashi S, Molnar Z, Kurotani T, Toyama K (2002) Prenatal development of neural excitation in rat thalamocortical projections studied by optical recording. Neuroscience 115:1231-1246.
Hill DN, Bermejo R, Zeigler HP, Kleinfeld D (2008) Biomechanics of the vibrissa motor plant in rat: rhythmic whisking consists of triphasic neuromuscular activity. J Neurosci 28:3438-3455.

Hirsch S, Luhmann HJ (2008) Pathway-specificity in N-methyl-daspartate receptor-mediated synaptic inputs onto subplate neurons. Neuroscience 153:1092-1102.

Hoerder-Suabedissen A, Molnar Z (2015) Development, evolution and pathology of neocortical subplate neurons. Nat Rev Neurosci 16:133-146.

Hübener M, Bonhoeffer T (2014) Neuronal plasticity: beyond the critical period. Cell 159:727-737.

Ikonomidou C, Turski L (2010) Antiepileptic drugs and brain development. Epilepsy Res 88:11-22.

Inacio AR, Nasretdinov A, Lebedeva J, Khazipov R (2016) Sensory feedback synchronizes motor and sensory neuronal networks in the neonatal rat spinal cord. Nat Commun 7:13060.

Istaphanous GK, Loepke AW (2009) General anesthetics and the developing brain. Curr Opin Anaesthesiol 22:368-373.

Iyer KK, Roberts JA, Hellstrom-Westas L, Wikström S, Hansen-Pupp I, Ley D, Vanhatalo S, Breakspear M (2015) Cortical burst dynamics predict clinical outcome early in extremely preterm infants. Brain 138:2206-2218.

Jhaveri S, Erzurumlu RS, Crossin K (1991) Barrel construction in rodent neocortex: role of thalamic afferents versus extracellular matrix molecules. Proc Natl Acad Sci U S A 88:4489-4493.

Johnson SL, Eckrich T, Kuhn S, Zampini V, Franz C, Ranatunga KM, Roberts TP, Masetto S, Knipper M, Kros CJ, Marcotti W (2011) Position-dependent patterning of spontaneous action potentials in immature cochlear inner hair cells. Nat Neurosci 14:711-718.

Kandler K, Katz LC (1998) Coordination of neuronal activity in developing visual cortex by gap junction-mediated biochemical communication. J Neurosci 18:1419-1427.

Kanold PO, Luhmann HJ (2010) The subplate and early cortical circuits. Annu Rev Neurosci 33:23-48.

Katz LC, Shatz CJ (1996) Synaptic activity and the construction of cortical circuits. Science 274:1133-1138.

Khazipov R, Luhmann HJ (2006) Early patterns of electrical activity in the developing cerebral cortex of human and rodents. Trends Neurosci 29:414-418.

Khazipov R, Minlebaev M, Valeeva G (2013) Early gamma oscillations. Neuroscience 250:240-252.

Khazipov R, Sirota A, Leinekugel X, Holmes GL, Ben-Ari Y, Buzsáki G (2004) Early motor activity drives spindle bursts in the developing somatosensory cortex. Nature 432:758-761.

Kidd FL, Isaac JTR (1999) Developmental and activity-dependent regulation of kainate receptors at thalamocortical synapses. Nature 400:569-573.

Kilb W, Frotscher M (2016) Cajal-Retzius cells: organizers of cortical development. e-Neuroforum 7:82-88.

Kilb W, Kirischuk S, Luhmann HJ (2011) Electrical activity patterns and the functional maturation of the neocortex. Eur $\mathrm{J}$ Neurosci 34:1677-1686.

Kilb W, Luhmann HJ (2003) Carbachol-induced network oscillations in the intact cerebral cortex of the newborn rat. Cereb Cortex 13:409-421.

Kirischuk S, Luhmann HJ, Kilb W (2014) Cajal-Retzius cells: update on structural and functional properties of these mystic neurons that bridged the 20th century. Neuroscience 275:33-46.

Kirkby LA, Sack GS, Firl A, Feller MB (2013) A role for correlated spontaneous activity in the assembly of neural circuits. Neuron 80:1129-1144.

Koolen N, Dereymaeker A, Räsänen O, Jansen K, Vervisch J, Matic V, Naulaers G, De Vos M, Van Huffel S, Vanhatalo S (2016) Early development of synchrony in cortical activations in the human. Neuroscience 322:298-307.

Kostovic I, Judas M (2010) The development of the subplate and thalamocortical connections in the human foetal brain. Acta Paediatr 99:1119-1127.

Kral A (2013) Auditory critical periods: A review from system's perspective. Neuroscience 247:117-133. 
Kullmann DM, Asztely F (1998) Extrasynaptic glutamate spillover in the hippocampus: evidence and implications. Trends Neurosci 21:8-14.

Kummer M, Kirmse K, Zhang C, Haueisen J, Witte OW, Holthoff K (2016) Column-like $\mathrm{Ca}(2+)$ clusters in the mouse neonatal neocortex revealed by three-dimensional two-photon $\mathrm{Ca}(2+)$ imaging in vivo. Neuroimage 138:64-75.

Landers M, Philip ZH (2006) Development of rodent whisking: trigeminal input and central pattern generation. Somatosens Mot Res 23:1-10.

Lebedeva J, Zakharov A, Ogievetsky E, Minlebaeva A, Kurbanov R, Gerasimova E, Sitdikova GF, Khazipov R (2015) Inhibition of cortical activity and apoptosis caused by ethanol in neonatal rats in vivo. Cereb Cortex. http://dx.doi.org/10.1093/cercor/bhv293.

Lebedeva YA, Zakharova AV, Sitdikova GF, Zefirov AL, Khazipov RN (2016) Ketamine-midazolam anesthesia induces total inhibition of cortical activity in the brain of newborn rats. Bull Exp Biol Med 161:15-19.

Lee JH, Zhang J, Wei L, Yu SP (2015) Neurodevelopmental implications of the general anesthesia in neonate and infants. Exp Neurol 272:50-60.

Lessmann V, Gottmann K, Malcangio M (2003) Neurotrophin secretion: current facts and future prospects. Prog Neurobiol 69:341-374.

Li H, Crair MC (2011) How do barrels form in somatosensory cortex? New Perspect Neurobehavioral Evol 1225:119-129.

Lohmann C, Finski A, Bonhoeffer T (2005) Local calcium transients regulate the spontaneous motility of dendritic filopodia. Nat Neurosci 8:305-312.

López-Bendito G, Molnár Z (2003) Thalamocortical development: how are we going to get there? Nat Rev Neurosci 4:276-289.

LoTurco JJ, Blanton MG, Kriegstein AR (1991) Initial expression and endogenous activation of NMDA channels in early neocortical development. J Neurosci 11:792-799.

Luhmann HJ (2013) Cajal-Retzius and subplate cells - transient cortical neurons and circuits. In: Rubenstein JLR, Rakic P, editors. Comprehensive developmental neuroscience: cellular migration and formation of neuronal connections. Amsterdam: Academic Press. p. 843-856.

Luhmann HJ (2017) Review of imaging network activities in developing rodent cerebral cortex in vivo. Neurophotonics 4:031202.

Luhmann HJ, Kilb W, Hanganu-Opatz IL (2009) Subplate cells: amplifiers of neuronal activity in the developing cerebral cortex. Front Neuroanat 3:19ff.

Luhmann HJ, Kirischuk S, Sinning A, Kilb W (2014) Early GABAergic circuitry in the cerebral cortex. Curr Opin Neurobiol 26:72-78.

Luhmann HJ, Reiprich RA, Hanganu IL, Kilb W (2000) Cellular physiology of the neonatal rat cerebral cortex: Intrinsic membrane properties, sodium and calcium currents. J Neurosci Res 62:574-584.

Luhmann HJ, Sinning A, Yang JW, Reyes-Puerta V, Stüttgen MC, Kirischuk S, Kilb W (2016) Spontaneous neuronal activity in developing neocortical networks: from single cells to large-scale interactions. Front Neural Circuits 10:40. http://dx.doi.org/ 10.3389/fncir.2016.00040.

Malk K, Metsaranta M, Vanhatalo S (2014) Drug effects on endogenous brain activity in preterm babies. Brain Dev 36:116-123.

Marcano-Reik AJ, Blumberg MS (2008) The corpus callosum modulates spindle-burst activity within homotopic regions of somatosensory cortex in newborn rats. Eur $J$ Neurosci 28:1457-1466.

Maric D, Maric I, Smith SV, Serafini R, Hu Q, Barker JL (1998) Potentiometric study of resting potential, contributing $\mathrm{K}+$ channels and the onset of $\mathrm{Na}+$ channel excitability in embryonic rat cortical cells. Eur J Neurosci 10:2532-2546.

McCabe AK, Chisholm SL, Picken-Bahrey HL, Moody WJ (2006) The self-regulating nature of spontaneous synchronized activity in developing mouse cortical neurones. J Physiol 577:155-167.
McCann ME, Bellinger DC, Davidson AJ, Soriano SG (2009) Clinical research approaches to studying pediatric anesthetic neurotoxicity. Neurotoxicology 30:766-771.

McCormick DA, Trent F, Ramoa AS (1995) Postnatal development of synchronized network oscillations in the ferret dorsal lateral geniculate and perigeniculate nuclei. J Neurosci 15:5739-5752.

Milh M, Kaminska A, Huon C, Lapillonne A, Ben-Ari Y, Khazipov R (2007) Rapid cortical oscillations and early motor activity in premature human neonate. Cereb Cortex 17:1582-1594.

Minlebaev M, Ben Ari Y, Khazipov R (2009a) NMDA receptors pattern early activity in the developing barrel cortex in vivo. Cereb Cortex 19:688-696.

Minlebaev M, Ben-Ari Y, Khazipov R (2007) Network mechanisms of spindle-burst oscillations in the neonatal rat barrel cortex in vivo. J Neurophysiol 97:692-700.

Minlebaev M, Ben-Ari Y, Khazipov R (2009b) NMDA receptors pattern early activity in the developing barrel cortex in vivo. Cereb Cortex 19:688-696.

Minlebaev M, Colonnese M, Tsintsadze T, Sirota A, Khazipov R (2011) Early gamma oscillations synchronize developing thalamus and cortex. Science 334:226-229.

Mitrukhina O, Suchkov D, Khazipov R, Minlebaev M (2015) Imprecise whisker map in the neonatal rat barrel cortex. Cereb Cortex 25:3458-3467.

Moody WJ, Bosma MM (2005) Ion channel development, spontaneous activity, and activity-dependent development in nerve and muscle cells. Physiol Rev 85:883-941.

Moreno-Juan V, Filipchuk A, Anton-Bolanos N, Mezzera C, Gezelius $\mathrm{H}$, Andres B, Rodriguez-Malmierca L, Susin R, Schaad O, Iwasato $T$, Schule $R$, Rutlin $M$, Nelson $S$, Ducret $S$, Valdeolmillos M, Rijli FM, López-Bendito G (2017) Prenatal thalamic waves regulate cortical area size prior to sensory processing. Nat Commun 8:14172.

Nadarajah B, Jones AM, Evans WH, Parnavelas JG (1997) Differential expression of connexins during neocortical development and neuronal circuit formation. $J$ Neurosci 17:3096-3111.

Nevalainen P, Rahkonen P, Pihko E, Lano A, Vanhatalo S, Andersson S, Autti T, Valanne L, Metsaranta M, Lauronen L (2015) Evaluation of somatosensory cortical processing in extremely preterm infants at term with MEG and EEG. Clin Neurophysiol 126:275-283.

Nguyen QT, Wessel R, Kleinfeld D (2004) Developmental regulation of active and passive membrane properties in rat vibrissa motoneurones. J Physiol 556:203-219.

Nikolic M, Gardner HA, Tucker KL (2013) Postnatal neuronal apoptosis in the cerebral cortex: physiological and pathophysiological mechanisms. Neuroscience 254:369-378.

Nimmervoll B, White R, Yang JW, An S, Henn C, Sun JJ, Luhmann HJ (2013) LPS-induced microglial secretion of TNF-alpha increases activity-dependent neuronal apoptosis in neonatal cerebral cortex. Cereb Cortex 23:1742-1755.

O'Leary DD, Sahara S (2008) Genetic regulation of arealization of the neocortex. Curr Opin Neurobiol 18:90-100.

Okawa H, Hoon M, Yoshimatsu T, Della Santina L, Wong ROL (2014) Illuminating the multifaceted roles of neurotransmission in shaping neuronal circuitry. Neuron 83:1303-1318.

Omidvarnia A, Fransson P, Metsaranta M, Vanhatalo S (2014) Functional bimodality in the brain networks of preterm and term human newborns. Cereb Cortex 24:2657-2668.

Owens DF, Kriegstein AR (1998) Patterns of intracellular calcium fluctuation in precursor cells of the neocortical ventricular zone. J Neurosci 18:5374-5388.

Patneau DK, Mayer ML (1990) Structure-activity relationships for amino acid transmitter candidates acting at $N$-methyl-D-aspartate and quisqualate receptors. J Neurosci 10:2385-2399.

Peinado A (2000) Traveling slow waves of neural activity: A novel form of network activity in developing neocortex. J Neurosci 20: NIL1-NIL6. 
Peinado A (2001) Immature neocortical neurons exist as extensive syncitial networks linked by dendrodendritic electrical connections. J Neurophysiol 85:620-629.

Petersen CC (2007) The functional organization of the barrel cortex. Neuron 56:339-355.

Poulet JF, Petersen CC (2008) Internal brain state regulates membrane potential synchrony in barrel cortex of behaving mice. Nature 454:881-885.

Rakic P (1976) Prenatal genesis of connections subserving ocular dominance in the rhesus monkey. Nature 261:467-471.

Rakic P, Ayoub AE, Breunig JJ, Dominguez MH (2009) Decision by division: making cortical maps. Trends Neurosci 32:291-301.

Ranasinghe S, Or G, Wang EY, levins A, McLean MA, Niell CM, Chau V, Wong PKH, Glass HC, Sullivan J, McQuillen PS (2015) Reduced cortical activity impairs development and plasticity after neonatal hypoxia ischemia. J Neurosci 35:11946-11959.

Rice FL (1985) Gradual changes in the structure of the barrels during maturation of the primary somatosensory cortex in the rat. $J$ Comp Neurol 236:496-503.

Rio-Bermudez C, Sokoloff G, Blumberg MS (2015) Sensorimotor processing in the newborn rat red nucleus during active sleep. $J$ Neurosci 35:8322-8332.

Rochefort NL, Garaschuk O, Milos RI, Narushima M, Marandi N, Pichler B, Kovalchuk Y, Konnerth A (2009) Sparsification of neuronal activity in the visual cortex at eye-opening. Proc Natl Acad Sci U S A 106:15049-15054.

Saleem AB, Lien AD, Krumin M, Haider B, Roson MR, Ayaz A, Reinhold K, Busse L, Carandini M, Harris KD (2017) Subcortical source and modulation of the narrowband gamma oscillation in mouse visual cortex. Neuron 93:315-322.

Sanes JR, Lichtman JW (1999) Development of the vertebrate neuromuscular junction. Annu Rev Neurosci 22:389-442.

Schouenborg J (2004) Learning in sensorimotor circuits. Curr Opin Neurobiol 14:693-697.

Sieben K, Hartung H, Wolff A, Hanganu-Opatz IL (2013) The melody of the immature brain. e-Neuroforum 4:11-17.

Spitzer NC (2015) Neurotransmitter Switching? No Surprise. Neuron 86:1131-1144.

Sun HY, An SM, Luhmann HJ, Kilb W (2014) Resonance properties of GABAergic intemeurons in immature GAD67-GFP mouse neocortex. Brain Res 1548:1-11.

Sun HY, Luhmann HJ, Kilb W (2012) Resonance properties of different neuronal populations in the immature mouse neocortex. Eur J Neurosci 36:2753-2762.

Sun JJ, Kilb W, Luhmann HJ (2010) Self-organization of repetitive spike patterns in developing neuronal networks in vitro. Eur $\mathrm{J}$ Neurosci 32:1289-1299.

Szwed M, Bagdasarian K, Ahissar E (2003) Encoding of vibrissal active touch. Neuron 40:621-630.

Thomas CG, Tian H, Diamond JS (2011) The relative roles of diffusion and uptake in clearing synaptically released glutamate change during early postnatal development. J Neurosci 31:4743-4754.

Tiriac A, Uitermarkt BD, Fanning AS, Sokoloff G, Blumberg MS (2012) Rapid whisker movements in sleeping newborn rats. Curr Biol 22:2075-2080.

Tolner EA, Sheikh A, Yukin AY, Kaila K, Kanold PO (2012) Subplate neurons promote spindle bursts and thalamocortical patterning in the neonatal rat somatosensory cortex. J Neurosci 32:692-702.

Tolonen M, Palva JM, Andersson S, Vanhatalo S (2007) Development of the spontaneous activity transients and ongoing cortical activity in human preterm babies. Neuroscience 145:997-1006.

Tritsch NX, Yi E, Gale JE, Glowatzki E, Bergles DE (2007) The origin of spontaneous activity in the developing auditory system. Nature 450:50-55.
Tyzio R, Cossart R, Khalilov I, Minlebaev M, Hübner CA, Represa A, Ben-Ari Y, Khazipov R (2006) Maternal oxytocin triggers a transient inhibitory switch in GABA signaling in the fetal brain during delivery. Science 314:1788-1792.

Uhlen P, Fritz N, Smedler E, Malmersjo S, Kanatani S (2015) Calcium signaling in neocortical development. Devel Neurobio 75:360-368.

Valiullina F, Akhmetshina D, Nasretdinov A, Mukhtarov M, Valeeva G, Khazipov R, Rozov A (2016) Developmental changes in electrophysiological properties and a transition from electrical to chemical coupling between excitatory layer 4 neurons in the rat barrel cortex. Front Neural Circuits 10.

van der Bourg A, Yang JW, Reyes-Puerta V, Laurenczy B, Wieckhorst M, Stuttgen MC, Luhmann HJ, Helmchen F (2016) Layer-specific refinement of sensory coding in developing mouse barrel cortex. Cereb Cortex. http://dx.doi.org/10.1093/cercor/ bhw280.

Vanhatalo S, Tallgren P, Andersson S, Sainio K, Voipio J, Kaila K (2002) DC-EEG discloses prominent, very slow activity patterns during sleep in preterm infants. Clin Neurophysiol 113:1822-1825.

Videman M, Tokariev A, Stjerna S, Roivainen R, Gaily E, Vanhatalo S (2014) Effects of prenatal antiepileptic drug exposure on newborn brain activity. Epilepsia 57:252-262.

Wagner-Golbs A, Luhmann HJ (2012) Activity-dependent survival of developing neocortical neurons depends on PI3K signalling. $J$ Neurochem 120:495-501.

Wang HC, Lin CC, Cheung R, Zhang-Hooks Y, Agarwal A, EllisDavies G, Rock J, Bergles DE (2015) Spontaneous activity of cochlear hair cells triggered by fluid secretion mechanism in adjacent support cells. Cell 163:1348-1359.

Wang XJ (2010) Neurophysiological and computational principles of cortical rhythms in cognition. Physiol Rev 90:1195-1268.

Warren RA, Jones EG (1997) Maturation of neuronal form and function in a mouse thalamo-cortical circuit. J Neurosci 17:277-295.

Weissman TA, Riquelme PA, Ivic L, Flint AC, Kriegstein AR (2004) Calcium waves propagate through radial glial cells and modulate proliferation in the developing neocortex. Neuron 43:647-661.

Xu HP, Burbridge TJ, Chen MG, Ge XX, Zhang YY, Zhou ZMJ, Crair MC (2015) Spatial pattern of spontaneous retinal waves instructs retinotopic map refinement more than activity frequency. Devel Neurobio 75:621-640.

Yang JM, Zhang J, Yu YQ, Duan SM, Li XM (2014) Postnatal development of 2 microcircuits involving fast-spiking interneurons in the mouse prefrontal cortex. Cereb Cortex 24:98-109.

Yang JW, An S, Sun JJ, Reyes-Puerta V, Kindler J, Berger T, Kilb W, Luhmann HJ (2013) Thalamic network oscillations synchronize ontogenetic columns in the newborn rat barrel cortex. Cereb Cortex 23:1299-1316.

Yang JW, Hanganu-Opatz IL, Sun JJ, Luhmann HJ (2009) Three patterns of oscillatory activity differentially synchronize developing neocortical networks in vivo. J Neurosci 29:9011-9025.

Yang JW, Reyes-Puerta V, Kilb W, Luhmann HJ (2016) Spindle bursts in neonatal rat cerebral cortex. Neural Plasticity.

Yu YC, He SJ, Chen S, Fu YH, Brown KN, Yao XH, Ma J, Gao KP, Sosinsky GE, Huang K, Shi SH (2012) Preferential electrical coupling regulates neocortical lineage-dependent microcircuit assembly. Nature 486:113-U139.

Yuste R, Peinado A, Katz LC (1992) Neuronal domains in developing neocortex. Science 257:665-669.

Zucker E, Welker WI (1969) Coding of somatic sensory input by vibrissae neurons in the rat's trigeminal ganglion. Brain Res 12:138-156. 